\title{
Qualitative research into the consumption of food with expired 'use by' dates
}

Area of research interest: Behaviour and perception

Study duration: 2021-03-22

Project status: Completed

Authors: Ipsos MORI

Date published: 31 August 2021

DOI: https://doi.org/10.46756/sci.fsa.qfy 700

This report details the findings from a rapid evidence review and primary qualitative research with thirty participants from England, Wales and Northern Ireland. During the primary research, participants took part in two depth interviews and an app-based diary between the 22nd March and the 4th April 2021 designed to explore the reasons why they consume food past the UBD.

Research report

England, Northern Ireland, Scotland and Wales

PDF

View Qualitative research into the consumption of food with expired 'use by' dates as PDF(Open in a new window) (2.39 MB) 